This item was submitted to Loughborough's Research Repository by the author.

Items in Figshare are protected by copyright, with all rights reserved, unless otherwise indicated.

\title{
Sustainable water management under future uncertainty with eco- engineering decision scaling
}

\section{PLEASE CITE THE PUBLISHED VERSION}

http://dx.doi.org/10.1038/nclimate2765

\section{PUBLISHER}

Nature Publishing Group

VERSION

AM (Accepted Manuscript)

\section{PUBLISHER STATEMENT}

This work is made available according to the conditions of the Creative Commons Attribution-NonCommercialNoDerivatives 4.0 International (CC BY-NC-ND 4.0) licence. Full details of this licence are available at: https://creativecommons.org/licenses/by-nc-nd/4.0/

\section{LICENCE}

CC BY-NC-ND 4.0

\section{REPOSITORY RECORD}

Poff, N. LeRoy, Casey M. Brown, Theodore E. Grantham, John H. Matthews, Margaret A. Palmer, Caitlin M. Spence, Robert L. Wilby, et al.. 2019. "Sustainable Water Management Under Future Uncertainty with Ecoengineering Decision Scaling”. figshare. https://hdl.handle.net/2134/19029. 


\section{Eco-engineering decision scaling as a foundation for sustainable water management under future hydrologic uncertainty}

* N. LeRoy Poff, Department of Biology and Graduate Degree Program in Ecology, Campus Mail 1878, Colorado State University, Fort Collins CO 80523 USA

Casey M. Brown, Civil and Environmental Engineering, University of Massachusetts, 12B Marston Hall, 130 Natural Resources Road, Amherst, Massachusetts 01003 USA

Theodore E. Grantham, U.S. Geological Survey, Fort Collins Science Center, 2150 Centre Avenue, Building C, Fort Collins, Colorado 80526 USA

John H. Matthews, Alliance for Global Water Adaptation, 7640 NW Hoodview Circle, Corvallis, OR 97330 USA

Margaret A. Palmer, National Socio-Environmental Synthesis Center, 1 Park Place, Annapolis Maryland 21401 USA

Caitlin M. Spence, Civil and Environmental Engineering, University of Massachusetts, 12B Marston Hall, 130 Natural Resources Road, Amherst, Massachusetts 01003 USA

Robert L. Wilby, Department of Geography, Loughborough University, Leicestershire, LE11 3TU, UK

Marjolijn Haasnoot, Department of Scenarios and Policy Analysis, PO Box 177, 2600 MH, Delft, The Netherlands; Delft University of Technology, Faculty of Technology, Policy \& Management, PO Box 5015, 2600 GA, Delft, The Netherlands 
Guillermo F Mendoza, U.S. Army Corps of Engineers, Institute for Water Resources, 7701 Telegraph Road, Alexandria, Virginia 22314 USA

Kathleen C. Dominique, Organisation for Economic Co-operation and Development (OECD), 2 rue André-Pascal, 75775 Paris, France

Andres Baeza, National Socio-Environmental Synthesis Center, 1 Park Place, Annapolis, Maryland 21401 USA 


\section{[Abstract]}

Managing freshwater resources sustainably under climatic uncertainty poses novel challenges. Rehabilitation of aging infrastructure and the construction of new dams are viewed as solutions to manage climate risk, but attaining the broader goal of freshwater sustainability will require expansion of the water resources management paradigm beyond narrow economic criteria to include socially-valued ecosystem functions and services. We introduce a new decision framework, called Eco-engineering decision scaling (EEDS) that explicitly and quantitatively explores tradeoffs in stakeholder-defined engineering and ecological performance metrics across a range of management actions and future climate states. We illustrate its potential application through a hypothetical case study of the Iowa River USA. EEDS holds promise as a powerful tool for operationalizing freshwater sustainability through incorporation of ecological vulnerability in the design and operation of resilient infrastructure.

\section{[Introduction]}

Securing the supply and equitable allocation of fresh water to support human wellbeing while sustaining healthy, functioning ecosystems is one of the grand environmental challenges of the 21st century, particularly in light of accelerating stressors from climate change, population growth, and economic development. Rehabilitation of aging infrastructure and construction of new infrastructure are now widely viewed as engineering solutions to mitigate future uncertainty in the hydrologic cycle ${ }^{1}$. Indeed, the construction of tens of thousands of dams in the 20th Century helped secure water supplies and fuel economic development in industrialized countries, and developing economies are now pursuing massive new infrastructure projects with thousands of new dams proposed for hydropower production and water supply security². 
Despite the economic stimulus provided by many dams historically, the global experience with dam building warns that traditional approaches to water infrastructure development in a rapidly changing world carry severe risks of economic and environmental failure. First, large water projects are very capital-intensive and long-lived, costing billions of dollars to plan, build, and maintain. Yet, they are vulnerable to biased economic analyses ${ }^{3}$, cost overruns and construction delays, and changing environmental, economic and social conditions that can diminish projected benefits ${ }^{4,5}$. Under a variable and changing climate, large water infrastructure even risk becoming stranded assets 6 . Second, the principles of economic efficiency inherent in cost-benefit analysis dominate project design and performance assessment, and integrating social and environmental benefits and costs into a comprehensive economic evaluation presents significant challenges ${ }^{7,8}$. These costs can be substantial, as evidenced by human displacement ${ }^{5,9}$, local species extinctions ${ }^{10}$, and the loss of ecosystem services such as floodplain fisheries and other amenities ${ }^{11,12}$.

As unanticipated economic, social and environmental costs accumulate with aging water infrastructure, society is investing in restoration projects to undo some of the long-term environmental degradation, including modifying flow releases from dams ${ }^{13,14}$ and in some cases dam removal ${ }^{15}$. As the global impairment of aquatic ecosystem function becomes increasingly documented and articulated 16,17 , a broader conception of sustainable water resources management that formulates environmental health as a necessary ingredient for water security and the social wellbeing it supports is urgently needed ${ }^{18-20}$. Notably, new national directives are emerging to develop and manage river ecosystems in less environmentally harmful and more sustainable ways, including in the US 21 , Europe 22,23 , and Australia ${ }^{24}$.

\section{Towards a more sustainable water resources management paradigm}

Here we ask if a more sustainable water management philosophy can be forged to guide investment in, and design of, water infrastructure while avoiding adverse, sometimes irreversible, social and 
environmental consequences. We consider "sustainable water management systems" to be those that meet the needs of society over the lifetime of the infrastructure and also maintain key ecological functions that support the long-term provision of ecosystem goods, services and values. These systems would embrace the principle of resilience, i.e., the capacity to persist with functional integrity with changing social and environmental conditions ${ }^{25}$. Indications of this emerging perspective are reflected in calls for greater focus on demand-side management, rather than supply-side solutions ${ }^{26}$, as well as "green" infrastructure approaches, including "soft-path" solutions ${ }^{27}$ and managed natural systems ${ }^{28}$. Deep uncertainty about future climate raises significant concerns about how to achieve long-term economic benefits and performance reliability of major water projects ${ }^{29,30}$. This unprecedented uncertainty renders traditional approaches to the design of long-lived infrastructure inadequate, requiring new decision-making approaches ${ }^{31}$. In the context of a changing (non-stationary) hydrologic cycle, incorporation of green design principles may be viewed as an investment in risk management by enhancing "robustness" (satisfactory performance under a wide range of uncertain futures) and "adaptive capacity" (the ability to be modified rapidly and economically in response to changing, unforeseen future conditions) $)^{32,33}$.

Planning for resilient, robust and adaptive water infrastructure to achieve social, economic and environmental objectives under a non-stationary future presents a novel challenges. First, contrasting paradigms in water resources engineering and in conservation ecology have dominated the broader societal debate about infrastructure design and operation over the past several decades $^{34,35}$, and these perspectives have typically been antagonistic. However, the fields of water resources engineering and conservation ecology are now independently re-examining long-held, foundational assumptions, in no small part due to concerns about climate change and other forms of non-stationarity (Box 1). These philosophical shifts are subsequently creating the possibility of revisiting ingrained presumptions about barriers to collaboratively attaining more sustainable water resources management. Second, methods for integrating ecological principles into water 
infrastructure design and operation to satisfy multiple objectives have been proposed ${ }^{8}$ but are not well established in practice ${ }^{36,37}$. So a key question emerges: How do we operationalize sustainable water management to couple engineering design principles with ecosystem requirements in the context of non-stationary stressors (e.g., changes in climate, water use, population growth and land use change)?

Fortuitously, a new analytical framework to climate adaptation planning has emerged that is appropriate for facilitating the sustainability dialogue between water resources engineers and conservation ecologists. Decision scaling ${ }^{38,39}$ was developed as an alternative to prevailing "top down" climate risk assessment methods in the water resources community that rely on projecting climate conditions several decades into the future, primarily through the use of global circulation models (GCMs). But GCM projections have large, irreducible uncertainties ${ }^{40}$ and poor capability to represent climatic variability (e.g., storm intensity-duration-frequencies) that water resources engineers require to design water infrastructure ${ }^{41,42}$. Thus, GCMs are often of limited use to water resources planners and decision makers attempting to understand and mitigate climate risks in the immediate management future ${ }^{43,44}$.

Decision scaling, by contrast, is a "bottom up" risk assessment approach that engages decision makers by starting with stakeholder-defined metrics that define acceptable system performance. System vulnerability is then assessed by evaluating the sensitivity of metrics (e.g., ability to meet water delivery targets) to a variety of non-stationary threats, such as climate change, demographic change, and economic trends that occur over management-relevant time scales. The decision scaling approach has been applied to evaluate climate risks to water management systems focused on engineering performance indicators, such as water supply reliability ${ }^{38}$, flood risk estimation ${ }^{45}$, and cost benefit analysis ${ }^{46}$, as well as climate-sensitive hydrologic indicators ${ }^{47}$. 
As in the water resources arena, ecosystem management is increasingly focused on reducing the vulnerability of sensitive species, ecological processes and natural resource production to a variety of non-stationary stressors through risk analysis ${ }^{48}$ and stakeholder-driven processes $^{49}$. For example, in regulated rivers, environmental flows to sustain desired ecological processes or conditions downstream of dams are often defined through vulnerability assessments involving scientists, government agencies and water users ${ }^{50}$. Similarly, "smart licenses" are being devised to protect the stakeholder-defined needs of both the environment and water users under anticipated climate variability and change ${ }^{51}$. More broadly, formal decision frameworks, such as structured decision making52, are being adopted by natural resource agencies to identify critical ecological thresholds, and guide adaptive management. Thus, decision scaling is consistent, in terms of process and scope, with bottom-up approaches that ecosystem managers are familiar with and often rely upon for decision making.

>> Box 1 here $<<<$

\section{Eco-engineering decision scaling (EEDS)}

Expansion of the existing decision scaling framework to consider both engineering and ecological performance affords a powerful new analytical approach to operationalize sustainable water resources management in the face of future hydrologic uncertainty. We refer to the integrated analysis of these complementary domains as eco-engineering decision scaling (EEDS). The approach builds from the multiple objective decision-scaling approach used for policy evaluation in the International Upper Great Lake Study ${ }^{53,54}$. The significance of EEDS is that it allows explicit evaluation of tradeoffs between engineering design and socially valued ecological performance associated with water resources development. More specifically, this tradeoff analysis occurs in the initial stages of project development, so that economic, engineering and ecological vulnerabilities 
can be simultaneously compared. Such early evaluation of ecosystem vulnerability is needed to reveal a range of potential design and management options in complex social-ecological systems ${ }^{55}$. This new approach is closely aligned with planning principles that engineers often follow, such as the Principles and Guidelines used by the US Corps of Engineers (USACE) ${ }^{56}$, and similar guidance documents in Europe ${ }^{57}$.

The EEDS framework strongly contrasts with approaches typically used to assess the environmental impacts of water infrastructure projects, and it can be summarized as a 5-step process shown visually in Figure 1 and described in detail in Box 2. Traditionally, initial project conception and design are driven by economic assessment of expected direct costs (e.g., financing, construction and maintenance) and benefits (e.g., revenue from hydropower production and water supply or avoided damages). Typically, only after identifying a set of competing economically viable alternatives, are environmental impacts potentially considered. In the EEDS approach, however, both economic and environmental performances are quantified and simultaneously compared across the range of future uncertainty. Ecological performance indicators must be clearly defined and quantitative, but significantly, they need not be monetized (which is often challenging or infeasible ${ }^{58}$ ) to allow comparison with traditional economic indicators. Furthermore, the EEDS approach can accommodate multiple performance metrics representing a diverse suite of economic, social and ecological objectives (e.g., ${ }^{8}$ ). However, for the sake of simplicity, we present only two metrics in our conceptual framework (Figure 1) and three metrics in our case study. Ultimately, stakeholders assess viable decision pathways based on the aggregate performance of all metrics and implement management options according to their values and preferences.

>>> Figure 1 here $<<<<$

>>> Box 2 here $<<<<$ 


\section{Iowa River case study}

Here, we illustrate the EEDS framework through a hypothetical example of a water resources decision problem for an existing flood management project. Coralville Dam was constructed in 1958 by the USACE on the Iowa River to protect Iowa City and downstream farmlands from flooding (Figure 2). Iowa City also has a series of floodplain levees in place to reduce flood risk. Since 1990, several severe runoff events have resulted in unscheduled water releases from the dam spillway, raising concerns that extreme floods are becoming more frequent and that current management operations are inadequate for controlling flood risk. We apply EEDS to evaluate the potential economic costs associated with altered climate regimes that elevate flood risk and explore how alternative flood-control management strategies could affect both engineering and ecological performance indicators. Extensive data on dam operations, system hydrology and flood inundation risk (Supplemental Information) make the system amenable to a hypothetical exploration of EEDS in a plausible management scenario.

$\gg>$ Figure 2 here $\ll<<<$

\section{Identification of performance indicators, thresholds and management scenarios (Step 1,}

Figure 1). We begin by defining stakeholder interests as primarily concerned with minimizing economic damages from flooding and with maintaining key ecological functions of the downstream aquatic and riparian ecosystems. Coralville Dam is primarily a flood-control project, and stakeholders receive economic benefits from flood protection in the form of avoided flood damages. We use Estimated Annual Costs (EAC) from flood damage as our engineering performance metric to evaluate costs of alternative strategies (see Supplementary Table 1). 
We assume stakeholders are willing to pay up to 1.5 times the long-term average costs (1959-2010) for the benefit of avoiding flood damages. This threshold is a 50\% increase in historical average EAC to allow for reasonable future management costs (e.g., building levees, reimbursing crop loss) that were ignored when calculating the current EAC.

The assessment of ecological performance is focused on key facets of the flow regime of known ecological importance ${ }^{59,60}$. First, we consider high flows that inundate floodplains and provide shallow, low-velocity, and highly productive habitat for freshwater organisms ${ }^{12}$. Many fish species time their spawning with floodplain inundation, and their young take advantage of nutrientrich floodplain habitats before entering the river channel61. The periodic inundation of floodplains is also essential to the health of riparian plant communities ${ }^{62}$. These ecological functions can be provided when floodplains are inundated for extended period of time, generally up to several weeks per year. Second, we consider the rate of flow fluctuations, which affect the availability and variation of in-channel habitat, and when artificially increased by reservoir release operations can adversely affect fish and other aquatic organisms ${ }^{63}$.

We defined two ecological performance metrics for our case study. A floodplain performance threshold was set as the historical annual average of floodplain area that is inundated for at least seven consecutive days, derived from estimated relationships between discharge and floodplain area from Coralville Dam to river mile 46 of the Iowa River (Supplementary Figure 2). This threshold is an intentionally simplified measure of floodplain function (i.e., timing of floods is not considered), and it is based on an assumed stakeholder preference for avoiding the loss of future floodplain functions relative to historical conditions. A second metric was defined by the magnitude of daily changes in outflows from the reservoir during periods when flows are being released rapidly from the reservoir in response to upstream inflows. We calculated a flow recession rate (difference between daily flow magnitudes) and set a threshold of $+30 \%$ of the natural daily recession rate, i.e., corresponding to the recession rates of unregulated inflows into 
the reservoir (see Supplementary Information for details). For both metrics, we make the simplifying assumption that biological communities and ecosystem functions will persist under future climate conditions if flood inundation patterns are maintained and excessive flow recession rates are avoided.

Our premise is that re-engineering of the current flood risk management system could provide the opportunity both to reduce the system's vulnerability to flood risk associated with rapid climate change and to satisfy ecological objectives for sustaining healthy downstream aquatic and riparian ecosystems. By quantifying the tradeoff space between the economic costs of engineering design and maintenance and the environmental benefits under alternative flood-risk management strategies, we aim to identify a robust decision option that meets both objectives. To examine these tradeoffs, we modeled engineering and ecological performance metrics over a range of future climates, subject to four hypothetical management strategies: (1) status quo (SQ), i.e., maintain current levee height and reservoir operating rules, (2) re-operate the reservoir (RR) by modifying existing reservoir operation rules to allow for increased emergency flow releases during the growing season, which would increase reservoir capacity for capturing storm runoff, (3) raise existing levees (RL) to increase flood protection around Iowa City, and (4) jointly re-operate the reservoir and raise levees $(\mathrm{RR}+\mathrm{RL})$.

Develop the decision systems model (Step 2, Figure 1). We used publicly available hydro-climatic data along with reservoir operations and hydraulic mapping data from the USACE (Supplementary Information) to develop a water management systems model of the Iowa River basin. We used this model to evaluate how the engineering performance indicator (EAC) and the ecological indicators (floodplain inundation area and flow recession rate) independently respond to climate variability (Supplementary Figure 1). A rainfall-runoff model of the basin was calibrated with historical 
climate and discharge data to predict daily inflows to Coralville Reservoir. Inflows were then fed into a reservoir operations model to estimate outflows to the Iowa River below the dam. Next, a river hydraulics model was used to estimate the daily downstream inundation area as a function of river discharge to allow estimation of annual costs (\$US), floodplain inundation, and flow recession rates. The systems model was modified for each of the four management strategies by specifying higher levees and/or alternative reservoir operation rules.

Vulnerability Analysis (Step 3 and 4, Figure 1). Engineering and ecological vulnerabilities were explored by evaluating the responses of performance indicators to management decisions under a wide range of plausible climate conditions. We generated a large stochastic input series of climate data ${ }^{64}$ with altered mean temperature, mean precipitation and daily precipitation coefficient of variation (Supplementary Information). Simulated data were then fed into the decision systems model (Supplementary Figure 1) to evaluate performance outcomes under specified management options and climate futures. Results of the vulnerability analysis were plotted across the range of climate variables relevant to flood risk management. As our primary demonstration of the EEDS framework, we evaluated how thresholds in performance indicators responded to deviation in predicted mean annual discharge and daily precipitation variability (CV), two hydro-climatic variables of primary interest in flood forecasting. As an alternative analysis, we explored vulnerability in a future climate space directly comparable to GCM climate projections, in which system performance was evaluated over a range of mean annual temperature and mean annual precipitation (Supplementary Information).

Our results (Figure 3) show how changes to the two hydro-climatic variables (displayed as orthogonal axes) affect system performance and potentially cross stakeholder-defined vulnerability thresholds. Each pixel represents a climate state simulated through the systems model. In Figure 3a, the engineering indicator (EAC, first column of figure) and the ecological indicator (floodplain inundation, second column) are plotted in a future climate state space defined by change in average 
annual daily flow and the variability of the daily precipitation series, for each of the four management options (rows). The indicators are expressed as the magnitude of change relative to mean historical conditions. The third column in Figure 3a displays the domain of "mutually acceptable performance," delineated by the white area that satisfies both the acceptable EAC and floodplain inundation performance criteria. In Figure 3b, the performance of the flow recession metric is plotted (first column) on the same axes and in response to the same four management options (rows). The mutually acceptable performance for the flow recession indicator is plotted along with the other two indicators (from Figure 3a) to show the overlapping performance for all three indicators. The mutually acceptable space can be quantified, and if desired, probabilities assigned to it ${ }^{65}$. Here visual inspection is sufficient.

>>> Figure 3 here $\ll<<$

Evaluation of tradeoff space with alternative decision models (Step 4 and 5, Figure 1). We evaluate the premise that system can be managed to meet both engineering and ecological objectives by examining the independent and joint responses of performance metrics to the different management options in Figure 3.

Figure 3a shows that for all four management options, the EAC metric is more likely to exceed the acceptable threshold level (dashed line) as precipitation CV increases (more frequent, large floods) and as average annual flow increases (wetter conditions). The floodplain performance indicator shows the reverse pattern, with wetter, more variable precipitation leading to greater floodplain inundation. Superimposing the EAC and floodplain inundation response surfaces reveals a domain of mutually acceptable performance (white space in the third column of Figure 3a). The status quo (SQ) management strategy, affords virtually no overlap in mutually acceptable climate space. Similarly, the RR has virtually no effect on the system's engineering performance relative to 
SQ. There is, however, a slight contraction in the climate space associated with catastrophic flood damages, i.e., those that are most expensive (e.g., $\geq 4$ times the historical EAC).

In contrast, the ecological floodplain performance indicator is significantly enhanced under the RR strategy, with floodplain inundation areas greater than mean historical conditions for all but the driest and least variable of simulated climate futures. The RL management action greatly reduces the vulnerability to unacceptable flood damage relative to SQ, yet it has no detectible effect on floodplain inundation. Only under wetter, more variable climates would floodplain inundation exceed the performance threshold under the RL action. When levees are raised in combination with reservoir re-operation $(\mathrm{RR}+\mathrm{RL})$, slightly higher costs are projected for EAC compared to the RL option (due to crop-damage costs incurred by controlled flood releases); however, floodplain inundation is achieved fully as in the RR option, so that the overall domain of mutually acceptable performance is larger than all other options (white space in Figure 3a). Thus, the RR+RL action would provide the most robust management strategy for an uncertain future, i.e., it would satisfy economic (EAC) and ecological goals (floodplain inundation) over the broadest range of future climate states.

Inclusion of the flow recession rate metric allows evaluation of management prospects for achieving "sustainable" management for more than two metrics simultaneously (Figure 3b). In general, the value for this ecological metric is sensitive to precipitation variability, but it remains below the target threshold ( $+30 \%$ of historical "natural" average recession rate) only when change in precipitation variability is low and mean daily flow is at or above $50 \%$ of the historical mean. None of the three active management options (RR, RL, RR+RL) modify the performance of this metric relative to the SQ option, which is perhaps not surprising Coralville's primary design function of flood control. 
By combining the flow recession rate metric with the EAC and floodplain inundation metrics, we can project a mutually acceptable space for all three metrics (Figure 3b, second column) that shows a more constrained domain of mutually acceptable performance compared to the previous 2-metric example (Figure 3a). However, the comparison of all management options again shows that the RR+RL action provides the largest opportunity to achieve performance objectives in an uncertain future. To potentially expand the climate domain under which the flow recession rate criterion is satisfied, future iterations of the EEDS process could consider additional changes in reservoir reoperations (i.e., restriction of flow release rates from the reservoir), a choice that stakeholders may or may not be willing to pursue.

In sum, these findings suggest that raising levees could provide substantial benefits in reducing flood damage under a wetter and more variable climate future. However, in drier and less variable future climate states, relatively low flood risks would make levees an unwise economic investment. Similarly, the results indicate that ecological benefits of floodplain inundation from reoperation would be realized under current and moderately wetter climate conditions. If the climate were to shift to extreme wet or dry states, the ecological benefits of re-operation are less clear for floodplains because in very dry years there would be insufficient water available to activate floodplains and the abundance of water in very wet years would make the effects of dam reoperation negligible.

We recognize that all simulated climate states evaluated in the system model are not equally plausible; however, the purpose of the vulnerability analysis is to determine how much the climate must change before the system is at risk of crossing key performance thresholds in the hypothetical example presented here. Once system failures are identified, judgments must be made regarding the plausibility of the conditions causing such failure using available climate information (such as downscaled GCMs, historical and paleo-climate records, etc.) and expert opinion about other sources of future hydrologic change (such as changes in runoff from land use change, growing 
human water demand, etc.). Confronting the performance under changing temperature and precipitation with climate change scenarios can help to identify if projected climate change is a threat and when a tipping point ${ }^{47}$ might be reached and require active management actions.

To place our results in the more conventional context of climate vulnerability analysis, we used downscaled, bias-corrected climate model ensembles (from CMIP3 and CMIP566) and plotted these projections over the system response surfaces to indicate the potential range of plausible future climate changes experienced in the Iowa River system by 2050 (Supplementary Figure 3). These GCM projections suggest that the system is vulnerable to projected climate changes and that the $\mathrm{RR}+\mathrm{RL}$ action is favored for reducing economic and ecological risks to projected climate changes over the next several decades.

Ultimately, decision makers in this system would have to assess the costs, benefits and political will to implement new flood control alternatives. In our example, it appears that raising the levees and changing operations confers the greatest robustness to climate change uncertainty. Timing of decisions and rates of change of climate are issues of detail that must be addressed by policy makers and stakeholders as they implement EEDS (or any form of adaptive management) in real world applications, similar to the climate-risk planning effort undertaken in the Great Lakes ${ }^{32}$. For example, the resources required to implement reservoir reoperations are likely less than constructing new levees and reversible, suggesting that a staged implementation approach may be appropriate, potentially triggered by evidence of worsening climate conditions, as has been described by the "adaptation pathways" approach, an emerging policy-analysis tool ${ }^{67,68}$.

\section{Eco-engineering Decision Scaling as a Sustainable Management Philosophy}

Deep uncertainty about future hydrology undermines traditional approaches for the design and operation of water infrastructure to achieve "reliable" performance ${ }^{29,30}$ and presents an 
unprecedented challenge for sustaining healthy, resilient freshwater ecosystems. On a global scale, current infrastructure (dams, irrigation works) is extensive and a dominant driver of freshwater ecosystem degradation ${ }^{16,60,69-71}$. Based on historical evidence, it is increasingly clear that human decisions on the design, location and operation (or re-operation) of water infrastructure such as dams will have both immediate and long-term effects on the health and resilience of freshwater ecosystem function and biodiversity ${ }^{72,73}$. A new paradigm of cooperation and collaboration among water resources engineers and conservation ecologists is needed to improve design and operate water infrastructure efficiently to meet both human and ecosystem needs in a socially acceptable and sustainable way.

EEDS is a framework that can provide a transparent process for operationalizing sustainable water management through integration of socio-environmental objectives in a decisionoriented vulnerability assessment framework. This approach has several strengths. First, it is designed to manage risk of uncertainty and provide guidance to managers and decision makers by focusing on vulnerability of engineering and ecological indicators to a range of hydrologic futures. It does not rely solely on downscaled GCM projections to assess climate risks but can include a wide range of sources of hydrologic non-stationarity, including historical and paleo-climate records and modeled land-use change information.

Second, EEDS represents a relatively small adjustment to existing water management decision-making processes. The key change is in assessing ecosystem vulnerabilities equally and early in the process, so that tradeoffs can be identified and addressed accurately and thus help inform social choices ${ }^{55}$. While engineering objectives of a project may sometimes be viewed as irreconcilable with ecological performance targets, it is possible that strategies for satisfying even modest ecological objectives may improve economic performance of water infrastructure systems, as has been shown with the restoration of coastal wetlands for wave-surge protection ${ }^{74}$ and incorporation of floodplains and wetlands in flood design ${ }^{61}$. Other applications of EEDS could be 
imagined for non-aquatic engineering design questions. Regardless of the specific project context, a full exploration of decision consequences on multiple performance indicators in a formal analytical framework can promote informed and transparent decision-making by enabling discussion about mutually satisfying solutions about water infrastructure.

Third, the EEDS framework can help inform a wide variety of management decisions that need to balance ecosystem sustainability with desired economic objectives. Ecological performance objectives can be construed broadly, e.g., from economically valuable fisheries to a highly desirable environmental amenity that has significant non-market value for stakeholders. As such, the decision framework is structured in a way that is relevant to those who are affected by planning and decisions. The EEDS framework is also well suited to "scale up" to whole basin planning to evaluate how planned infrastructure projects could meet both economic performance and ecosystem services under changing climate in large rivers in the developing world ${ }^{72 . .}$

Finally, the EEDS framework can inform decisions regarding existing water infrastructure systems, such as re-operation of downstream discharge releases from dams (as illustrated in our Iowa River case study), or decommissioning of projects. In developed countries such as the United States, thousands of dams built in the early to mid-20th century no longer provide their intended benefits due to infrastructure decay, the loss of storage capacity from sediment accumulation, and increased hazard risk due to downstream development ${ }^{63}$. The convergence of aging infrastructure with growing concern over trends of environmental degradation has provided unprecedented opportunities for ecosystem restoration ${ }^{64}$. However, climate change and uncertainty about ecosystem responses to infrastructure modification or removal make it difficult to identify economically and environmentally acceptable strategies. While dam re-operation is generally viewed as a mechanism to buffer aquatic ecosystems against climate change in regulated rivers ${ }^{14}$, EEDS analysis provides an analytical framework for evaluating the consequences of different 
management options by explicitly quantifying tradeoffs among economic and environmental objectives under plausible sources of hydrologic non-stationarity.

\section{Conclusion}

Integrated management of Earth's water resources for both human economic needs and ecosystem health is increasingly recognized as essential to societal wellbeing ${ }^{20,75}$. However, progress towards more sustainable forms of water management is hampered by conflicting interests, existing economic policies, inflexible infrastructure design and lack of quantitative, transparent tools to facilitate critical decision-making. The debate around the construction of water infrastructure is long-standing 4,35 and it will no doubt continue in the face of extensive proposed dam building globally². However, our aim here is not to advocate for or against the necessity of water infrastructure, but rather to argue that, in those situations where water infrastructure will be constructed or re-operated, water sustainability can be more effectively achieved where conservation ecologists collaboratively engage with water resources engineers to incorporate ecosystem performance goals into water infrastructure design and operation.

A key, ongoing challenge for rational management of the Earth's water resources is to provide a practical approach to assist planners and decision-makers in navigating complex problems and diverse interest groups who are confronted by uncertain and changing conditions. As effective adaptive decision-making is most likely to succeed where stakeholders have significant input into the process of tradeoff analysis, we believe the EEDS offers the potential to serve as the foundation of a new management paradigm that advances freshwater sustainability while meeting human needs for water. Of course, there is scope for further refinement of this framework, such as how best to accommodate future changes in damage functions (e.g., due to population growth), shifts in ecological requirements under transient climate and socio-economic conditions, and optimal sequences of management actions. A promising future possibility is to link EEDS with 
emerging techniques that help to identify when adaptation actions should be taken, such as dynamic adaptation pathways approaches ${ }^{68,76}$. In any case, managing the future will necessarily occur in an adaptive context; therefore, equally robust monitoring and evaluation plans will be needed to ensure that decisions are drawing upon the best available information when evaluating the consequences of alternative management strategies.

Box 1. Shifting paradigms in water resources engineering and conservation ecology

Rapid climate change, population growth, and economic trends are generating unprecedented uncertainty about how to achieve sustainability targets for water management and ecosystem conservation and opportunities to find common ground. First, traditional water resources engineering is struggling with climate non-stationarity (unknowable uncertainty about future hydrologic conditions) and seeking new approaches to guide infrastructure planning and avenues for secure economic investment under a wide range of climate scenarios ${ }^{77}$. Second, climate variability and change plus the pervasive effects of human activities on ecosystems are broadly challenging conservation and restoration ecology, which have traditionally defined ecosystem management targets by reference to historical ("natural") conditions and focused on habitat reserve strategies ${ }^{78}$. Emerging perspectives in aquatic ecology now place biological conservation in the context of highly altered and non-stationary hydrosystems that require active management within human-dominated landscapes to preserve desirable ecosystem attributes ${ }^{79-81}$. These perspectives align with a broader conservation approach of "managing for resilience" 82 , which focuses on maintaining key processes and relationships in social-ecological systems so that they are robust to a wide range and variety of perturbation from climate or other stressors. This paradigm 
represents a departure from traditional conservation biology in that it emphasizes the endurance of system wide properties, rather than individual species, and promotes "reconciliation" of conservation objectives with the alteration of natural systems by human influences ${ }^{81,83}$. Together, emerging new paradigms in ecology and engineering are giving rise to potential new levels of cooperation and communication across these (traditionally antagonistic) disciplines. For example, ecologists are now developing socially contextualized conservation tools to inform water infrastructure management ("environmental flows"50,84,85) and water resources engineers are actively exploring how to incorporate these into existing infrastructure operations ${ }^{86,87}$ and multiple objective evaluation approaches ${ }^{88}$.

Box 2. Eco-engineering decision-scaling framework: an iterative 5-step process

The EEDS framework comprises five distinct and iterative steps (Figure 1). Step 1 is a stakeholderdriven process to identify a set of possible management decision options (e.g., $D_{1}, D_{2}$, and $D_{3}$ in the figure), performance indicators (engr and ecol) and user-specified thresholds ( $\theta_{1}$ and $\theta_{2}$ ) that define conditions under which the system no longer performs at an "acceptable" level. Performance indicators represent key system values or services important to stakeholders. In the engineering domain, performance criteria could include, for example, reliability of water supply, reduction in expected flood damage, or the internal rate of return for a proposed project. Ecological performance metrics are also identified to represent desirable environmental conditions or ecosystem services. Such performance criteria could include maintaining a minimum population size for target species, or sustaining a specified areal coverage of riparian forests via overbank flows. Other metrics representing important ecosystem processes, such as flood regimes or sediment-transport dynamics, could also be selected, depending on the nature of the study system, stakeholder preferences, and data availability. Similarly, more spatially extensive metrics such as 
connectivity among river segments could be developed for multiple infrastructure components, such as siting of dams throughout a river network.

Step 2 in EEDS requires development of a systems decision model that relates changes in climate and other stressors (e.g., population growth, shifts in water demand, land use change) to engineering and ecological performance outcomes. This would typically be implemented through any of several integrated water management models, such as the Water Evaluation and Planning $\left(\mathrm{WEAP}^{\odot}\right)$ system $^{89}$, or by linking basin hydrologic models (e.g., Variable Infiltration Capacity $(\mathrm{VIC})^{90}$ ), Distributed Hydrology-Soil-Vegetation-Model (DHSVM) ${ }^{91}$, etc.) with water management operating rules to calculate resultant performance indicators. A systems decision model provides the basis for evaluating the consequences of management options across a wide range of plausible values in key climate variables and other system stressors ( $x_{1}$ and $x_{2}$ in the figure).

In Step 3, a vulnerability analysis ("stress test"45) is performed to exhaustively evaluate how the engineering and ecological performance indicators of the system respond to changes in climate or other input parameters (i.e., the $x_{1}$ and $x_{2}$ variables). Performance indicators can be mapped visually in a plausible climate space (see Supplementary Information for details) to identify the conditions under which the system fails to satisfy both engineering and ecological indicators. The sensitivity of system to input and model parameters can also be explored to identify variables and sources of uncertainty that have the greatest influence on performance outcomes ${ }^{35}$. For example, an assessment of system vulnerability to a wide range of plausible states may reveal that non-climate factors (e.g., population growth and shifts in water demand) are of greater concern than potential changes in climate variability.

The approach can also highlight combinations of specific changes that lead to failure, such as a given magnitude of warming and drying. Then, the acceptability of a particular decision can be 
assessed according to the degree to which the engineering and ecological performance indicators are mutually satisfied over a continuous range of plausible future conditions.

In Step 4, alternative management options can be specified in the systems model to evaluate how the multiple domains of acceptable performance and their mutual overlap vary among the available management options. The option with the greatest overlap in the domains of acceptable performance among indicators would be considered as the most robust and sustainable in the face of future uncertainty. In this way, decisions are assessed according to their ability to provide mutually robust performance, i.e., satisfy both the engineering system and ecosystem performance indicators over the widest range of future uncertain conditions.

Finally, in Step 5, decision makers (stakeholders, policy makers) assess the feasibility of either moving forward with the most promising option or developing new decision options that may better satisfy objectives, thus reiterating the process. Decision makers may also decide to consider alternative performance metrics or preference thresholds for re-evaluation. Considerations that affect the political or institutional feasibility of some options may be difficult to incorporate into computational models, necessitating the engagement of policy makers throughout the decision process to ensure feasible and relevant options. In this way, EEDS is an iterative decision-making process consistent with emerging adaptive and ecosystem-based water management frameworks ${ }^{52,92}$. 


\section{Acknowledgements}

We thank Jonathan Friedman and four anonymous reviewers for their helpful comments. Thanks also go to Scott Steinschneider for developing the stochastic weather generator for the Iowa River Basin, Sungwook Wi for the VIC hydrologic model development, Danica LeFever for support in developing the reservoir systems model, and Rolf Olsen for his help in providing hydraulic modeling tools and economic information for the Coralville Lake flood control system. Additional support for Casey Brown and Caitlin Spence was provided by the NSF CAREER Award (CBET1054762). The views in this article are those of the authors and do not necessarily reflect the views of the OECD or its member countries. This research was supported through a series of workshops at the National Socio-Environmental Synthesis Center (SESYNC) under funding received from the National Science Foundation DBI-1052875.

\section{Author Contributions}

N.L.P. and J.H.M. conceived the original project. N.L.P., T.E.G. and C.M.B. led the drafting of the text, with contributions from all other authors. C.M.S., C.M.B., T.E.G. and N.L.P. led the case study analysis. All authors contributed to the intellectual content.

\section{Author Contributions}

The authors declare we have no competing financial interests. 


\section{References}

1 International Commission on Large Dams. <http://www.icold-cigb.org/> (2014).

2 Zarfl, C., Lumsdon, A., Berlekamp, J., Tydecks, L. \& Tockner, K. A global boom in hydropower dam construction. Aquat Sci, 1-10 (2014).

3 Stakhiv, E. Z. Pragmatic approaches for water management under climate change uncertainty. Journal of the American Water Resources Association 47, 1183-1196 (2011).

4 Ansar, A., Flyvbjerg, B., Budzier, A. \& Lunn, D. Should we build more large dams? The actual costs of hydropower megaproject development. Energy Policy 69, 43-56 (2014).

$5 \quad$ World Commission on Dams. Dams and Development: A New Framework for Decision-Making (Earthscan Publications Ltd, London, 2000).

6 Organisation for Economic Co-operation and Development (OECD). Water and Climate Change Adaptation: Policies to Navigate Uncharted Waters (OECD Publishing, Paris, 2013).

7 Pearce, D., Atkinson, G. \& Mourato, S. Cost-Benefit Analysis and the Environment: Recent Developments (OECD, Paris, 2006).

8 Brown, P. H., Tullos, D., Tilt, B., Magee, D. \& Wolf, A. T. Modeling the costs and benefits of dam construction from a multidisciplinary perspective. Journal of Environmental Management 90, S303-S311 (2009).

9 Richter, B. D. et al. Lost in development's shadow: The downstream human consequences of dams. Water Alternatives 3, 14-42 (2010).

10 Riedy Liermann, C., Nilsson, C., Robertson, J. \& Ng, R. Y. Implications of dam obstruction for global freshwater fish diversity. BioScience 62, 539-548 (2012).

11 Auerbach, D. A., Deisenroth, D. B., McShane, R. R., McCluney, K. E. \& Poff, N. L. Beyond the concrete: Accounting for ecosystem services from free-flowing rivers. Ecosystem Services 10, 1-5 (2014).

12 Tockner, K. \& Stanford, J. A. Riverine flood plains: present state and future trends. Environmental conservation 29, 308-330 (2002).

13 Olden, J. D. et al. Are large-scale flow experiments informing the science and management of freshwater ecosystems? Frontiers in Ecology and the Environment 12, 176-185 (2014).

14 Watts, R. J., Richter, B. D., Opperman, J. J. \& Bowmer, K. H. Dam reoperation in an era of climate change. Marine and Freshwater Research 62, 321-327 (2011).

15 Lovett, R. A. Dam removals: Rivers on the run. Nature 511, 521-523 (2014).

16 Vörösmarty, C. J. et al. Global threats to human water security and river biodiversity. Nature 467, 555-561 (2010). 
17 Lehner, B. et al. High-resolution mapping of the world's reservoirs and dams for sustainable river-flow management. Frontiers in Ecology and the Environment 9, 494-502 (2011).

18 Millennium Ecosystem Assessment. Ecosystems and Human Well-Being: Wetlands and Water Synthesis (World Resources Institute, Washington D.C., 2005).

19 Griggs, D. et al. Policy: Sustainable development goals for people and planet. Nature 495, 305-307 (2013).

20 Rockström, J. et al. The unfolding water drama in the Anthropocene: Towards a resiliencebased perspective on water for global sustainability. Ecohydrology 7, 1249-1261 (2014).

21 Interagency Climate Change Adaptation Task Force. National Action Plan: Priorities for Managing Freshwater Resources in a Changing Climate (2011).

22 European Commission. Directive 2000/60/EC of the European Parliament and of the Council of 23 October 2000 Establishing a Framework for Community Action in the Field of Water Policy (European Commission, Brussels, 2000).

23 European Commission. Ecological Flows in the Implementation of the Water Framework Directive (European Commission, Brussels, 2015).

24 Australian National Water Commission. National Water Initiative (2005).

25 Folke, C. et al. Resilience thinking: Integrating resilience, adaptability and transformability. Ecology and Society 15, 20 (2010).

26 Pittock, J. \& Lankford, B. A. Environmental water requirements: Demand managment in an era of water scarcity. Journal of Integrative Environmental Sciences 7, 75-93 (2010).

27 Gleick, P. H. Global freshwater resources: Soft-path solutions for the 21st century. Science 302, 1524-1528 (2003).

28 Tzoulas, K. et al. Promoting ecosystem and human health in urban areas using Green Infrastructure: A literature review. Landscape and Urban Planning 81, 167-178 (2007).

29 Milly, P. C. D. et al. Stationarity Is dead: Whither water management? Science 319, 573-574 (2008).

30 Brown, C. The end of reliability. Journal of Water Resources Planning and Management 136, 143-145 (2010).

31 Hallegatte, S. Strategies to adapt to an uncertain climate change. Global Environmental Change 19, 240-247 (2009).

32 Haasnoot, M., Middelkoop, H., Van Beek, E. \& Van Deursen, W. A method to develop sustainable water management strategies for an uncertain future. Sustainable Development 19, 369-381 (2011).

33 Walker, W. E., Haasnoot, M. \& Kwakkel, J. H. Adapt or perish: A review of planning approaches for adaptation under deep uncertainty. Sustainability 5, 955-979 (2013). 
34 Reuss, M. Ecology, planning, and river management in the United States: Some historical reflections. Ecology and Society 10, 34 (2005).

35 Muller, M. The 'nexus' as a step back towards a more coherent water resource management paradigm. Water Alternatives 8, 675-694 (2015).

36 La Quesne, T., Kendy, E. \& Weston, D. The Implementation Challenge: Taking Stock of Government Policies to Protect and Restore Environmental Flows (World Wildlife Fund, 2010).

37 Pahl-Wostl, C. et al. Environmental flows and water governance: Managing sustainable water uses. Current Opinion in Environmental Sustainability 5, 341-351(2013).

38 Brown, C., Ghile, Y., Laverty, M. \& Li, K. Decision scaling: Linking bottom-up vulnerability analysis with climate projections in the water sector. Water Resources Research 48, W09537 (2012).

39 Brown, C., Werick, W., Leger, W. \& Fay, D. A Decision-Analytic Approach to Managing Climate Risks: Application to the Upper Great Lakes. Journal of the American Water Resources Association 47, 524-534 (2011).

40 Stainforth, D. A., Allen, M. R., Tredger, E. R. \& Smith, L. A. Confidence, uncertainty and decision-support relevance in climate predictions. Philosophical Transactions of the Royal Society A: Mathematical, Physical and Engineering Sciences 365, 2145-2161 (2007).

41 Rocheta, E., Sugiyanto, M., Johnson, F., Evans, J. \& Sharma, A. How well do general circulation models represent low-frequency rainfall variability? Water Resources Research 50, 21082123 (2014).

42 Sun, Y., Solomon, S., Dai, A. \& Portmann, R. W. How often does it rain? Journal of Climate 19, 916-934 (2006).

43 Wilby, R. L. \& Dessai, S. Robust adaptation to climate change. Weather 65, 180-185 (2010).

44 Weaver, C. P. et al. Improving the contribution of climate model information to decision making: The value and demands of robust decision frameworks. Wiley Interdisciplinary Reviews: Climate Change 4, 39-60 (2013).

45 Steinschneider, S., Wi, S. \& Brown, C. The integrated effects of climate and hydrologic uncertainty on future flood risk assessments. Hydrological Processes (2014).

46 Ghile, Y., Taner, M., Brown, C., Grijsen, J. \& Talbi, A. Bottom-up climate risk assessment of infrastructure investment in the Niger River Basin. Climatic change 122, 97-110 (2014).

47 Singh, R., Wagener, T., Crane, R., Mann, M. \& Ning, L. A vulnerability driven approach to identify adverse climate and land use change combinations for critical hydrologic indicator thresholds: Application to a watershed in Pennsylvania, USA. Water Resources Research 50, 3409-3427 (2014). 
48 U.S. Environmental Protection Agency. Aquatic Ecosystems, Water Quality, and Global Change: Challenges of Conducting Multi-Stressor Vulnerability Assessments (U.S. Environmental Protection Agency, Washington, DC, 2011).

49 Reed, M. S. Stakeholder participation for environmental management: A literature review. Biological Conservation 141, 2417-2431 (2008).

50 Poff, N. L. et al. The ecological limits of hydrologic alteration (ELOHA): A new framework for developing regional environmental flow standards. Freshwater Biology 55, 147-170 (2010).

51 Wilby, R. L., Fenn, C. R., Wood, P. J., Timlett, R. \& LeQuesne, T. Smart licensing and environmental flows: Modeling framework and sensitivity testing. Water Resources Research 47, W12524 (2011).

52 Gregory, R. et al. Structured Decision Making: A Practical Guide to Environmental Management Choices (John Wiley \& Sons, 2012).

53 Moody, P. \& Brown, C. Modeling stakeholder-defined climate risk on the Upper Great Lakes. Water Resources Research 48, W10525 (2012).

54 Moody, P. \& Brown, C. Robustness indicators for evaluation under climate change: Application to the upper Great Lakes. Water Resources Research 49, 3576-3588 (2013).

55 Kareiva, P. M. Dam choices: Analyses for multiple needs. Proceedings of the National Academy of Sciences 109, 5553-5554 (2012).

56 Armah, J. et al. Principles and Guidelines for Evaluating Federal Water Projects: US Army Corps of Engineers Planning and the Use of Benefit Cost Analysis (2009).

$57 \quad$ Kwadijk, J. C. et al. Using adaptation tipping points to prepare for climate change and sea level rise: a case study in the Netherlands. Wiley Interdisciplinary Reviews: Climate Change 1, 729-740 (2010).

58 Millennium Ecosystem Assessment. Ecosystems and Human Well-Being: General Synthesis (World Resources Institute, Washington D.C., 2005).

59 Poff, N. L. et al. The natural flow regime. BioScience 47, 769-784 (1997).

60 Bunn, S. E. \& Arthington, A. H. Basic principles and ecological consequences of altered flow regimes for aquatic biodiversity. Environmental Management 30, 492-507 (2002).

61 Opperman, J. J., Luster, R., McKenney, B. A., Roberts, M. \& Meadows, A. W. Ecologically functional floodplains: connectivity, flow regime, and scale. Journal of the American Water Resources Association 46, 211-226 (2010).

62 Nilsson, C. \& Svedmark, M. Basic principles and ecological consequences of changing water regimes: Riparian plant communities. Environmental management 30, 468-480 (2002).

63 Cushman, R. M. Review of ecological effects of rapidly varying flows downstream from hydroelectric facilities. North American Journal of Fisheries Management 5, 330-339 (1985). 
64 Steinschneider, S. \& Brown, C. A semiparametric multivariate, multisite weather generator with low-frequency variability for use in climate risk assessments. Water Resources Research 49, 7205-7220 (2013).

65 Whateley, S., Steinschneider, S. \& Brown, C. A climate change range-based method for estimating robustness for water resources supply. Water Resources Research 50, 8944-8961 (2014).

66 Maurer, E., Wood, A., Adam, J., Lettenmaier, D. \& Nijssen, B. A long-term hydrologically based dataset of land surface fluxes and states for the conterminous United States. Journal of Climate 15, 3237-3251 (2002).

67 Haasnoot, M., Middelkoop, H., Offermans, A., Van Beek, E. \& Van Deursen, W. Exploring pathways for sustainable water management in river deltas in a changing environment. Climatic change 115, 795-819, doi:10.1007/s10584-012-0444-2 (2012).

68 Ranger, N., Reeder, T. \& Lowe, J. Addressing 'deep'uncertainty over long-term climate in major infrastructure projects: Four innovations of the Thames Estuary 2100 Project. EURO Journal on Decision Processes 1, 233-262 (2013).

69 Grill, G. et al. An index-based framework for assessing patterns and trends in river fragmentation and flow regulation by global dams at multiple scales. Environmental Research Letters 10, 015001 (2015).

70 Dudgeon, D. et al. Freshwater biodiversity: Importance, threats, status and conservation challenges. Biological Reviews 81, 163-182 (2006).

71 Poff, N. L., Olden, J. D., Merritt, D. M. \& Pepin, D. M. Homogenization of regional river dynamics by dams and global biodiversity implications. Proceedings of the National Academy of Sciences 104, 5732-5737 (2007).

72 Jager, H. I., Efroymson, R. A., Opperman, J. J. \& Kelly, M. R. Spatial design principles for sustainable hydropower development in river basins. Renewable and Sustainable Energy Reviews 45, 808-816 (2015).

73 Poff, N. L. Rivers of the Anthropocene? Frontiers in Ecology and the Environment 12, 427427 (2014).

74 Gedan, K., Kirwan, M., Wolanski, E., Barbier, E. \& Silliman, B. The present and future role of coastal wetland vegetation in protecting shorelines: Answering recent challenges to the paradigm. Climatic change 106, 7-29 (2011).

75 Declaration, Brisbane. The Brisbane Declaration: Environmental flows are essential for freshwater ecosystem health and human well-being in 10th International River Symposium, Brisbane, Australia (2007).

76 Haasnoot, M., Kwakkel, J. H., Walker, W. E. \& ter Maat, J. Dynamic adaptive policy pathways: A method for crafting robust decisions for a deeply uncertain world. Global Environmental Change 23, 485-498 (2013). 
77 Hallegatte, S., Shah, A., Lempert, R., Brown, C. \& Gill, S. Investment Decision Making Under Deep Uncertainty: Application to Climate Change (World Bank Group, Washington D.C., 2012).

78 Wiens, J. A. \& Hobbs, R. J. Integrating Conservation and Restoration in a Changing World. BioScience 65, 302-312 (2015).

79 Humphries, P. \& Winemiller, K. O. Historical impacts on river fauna, shifting baselines, and challenges for restoration. BioScience 59, 673-684 (2009).

80 Acreman, M. et al. Environmental flows for natural, hybrid, and novel riverine ecosystems in a changing world. Frontiers in Ecology and the Environment 12, 466-473 (2014).

81 Moyle, P. B. Novel aquatic ecosystems: The new reality for streams in California and other mediterranean climate regions. River Research and Applications (2013).

82 Allen, C. R., Cumming, G. S., Garmestani, A. S., Taylor, P. D. \& Walker, B. H. Managing for resilience. Wildlife Biology 17, 337-349 (2011).

83 Hobbs, R. J., Higgs, E. \& Harris, J. A. Novel ecosystems: implications for conservation and restoration. Trends in Ecology \& Evolution 24, 599-605 (2009).

84 Richter, B. D., Mathews, R., Harrison, D. L. \& Wigington, R. Ecologically sustainable water management: Managing river flows for ecological integrity. Ecological Applications 13, 206224 (2003).

85 Arthington, A. H. Environmental Flows: Saving Rivers in the Third Millennium (University of California Press, 2012).

86 Suen, J.-P. \& Eheart, J. W. Reservoir management to balance ecosystem and human needs: Incorporating the paradigm of the ecological flow regime. Water Resources Research 42, W03417 (2006).

87 Yin, X.-A., Yang, Z.-F. \& Petts, G. E. Reservoir operating rules to sustain environmental flows in regulated rivers. Water Resources Research 47, W08509 (2011).

88 Hermoso, V. et al. Systematic planning for river rehabilitation: integrating multiple ecological and economic objectives in complex decisions. Freshwater Biology 57, 1-9 (2012).

89 Stockholm Environment Institute. Water Evaluation and Planning (WEAP) System, <http://www.weap21.org/> (2015).

90 Gao, H. et al. Water budget record from Variable Infiltration Capacity (VIC) model in Algorithm Theoretical Basis Document for Terrestrial Water Cycle Data Records (2010).

91 Cuo, L., Lettenmaier, D. P., Mattheussen, B. V., Storck, P. \& Wiley, M. Hydrologic prediction for urban watersheds with the Distributed Hydrology-Soil-Vegetation Model. Hydrological Processes 22, 4205-4213 (2008). 
92 Schoeman, J., Allan, C. \& Finlayson, C. M. A new paradigm for water? A comparative review of integrated, adaptive and ecosystem-based water management in the Anthropocene. International Journal of Water Resources Development 30, 377-390 (2014). 


\section{Figure Legends}

Figure 1. Eco-engineering decision scaling (EEDS) framework showing details of five steps required for the process. See text for detailed description of each step.

Figure 1

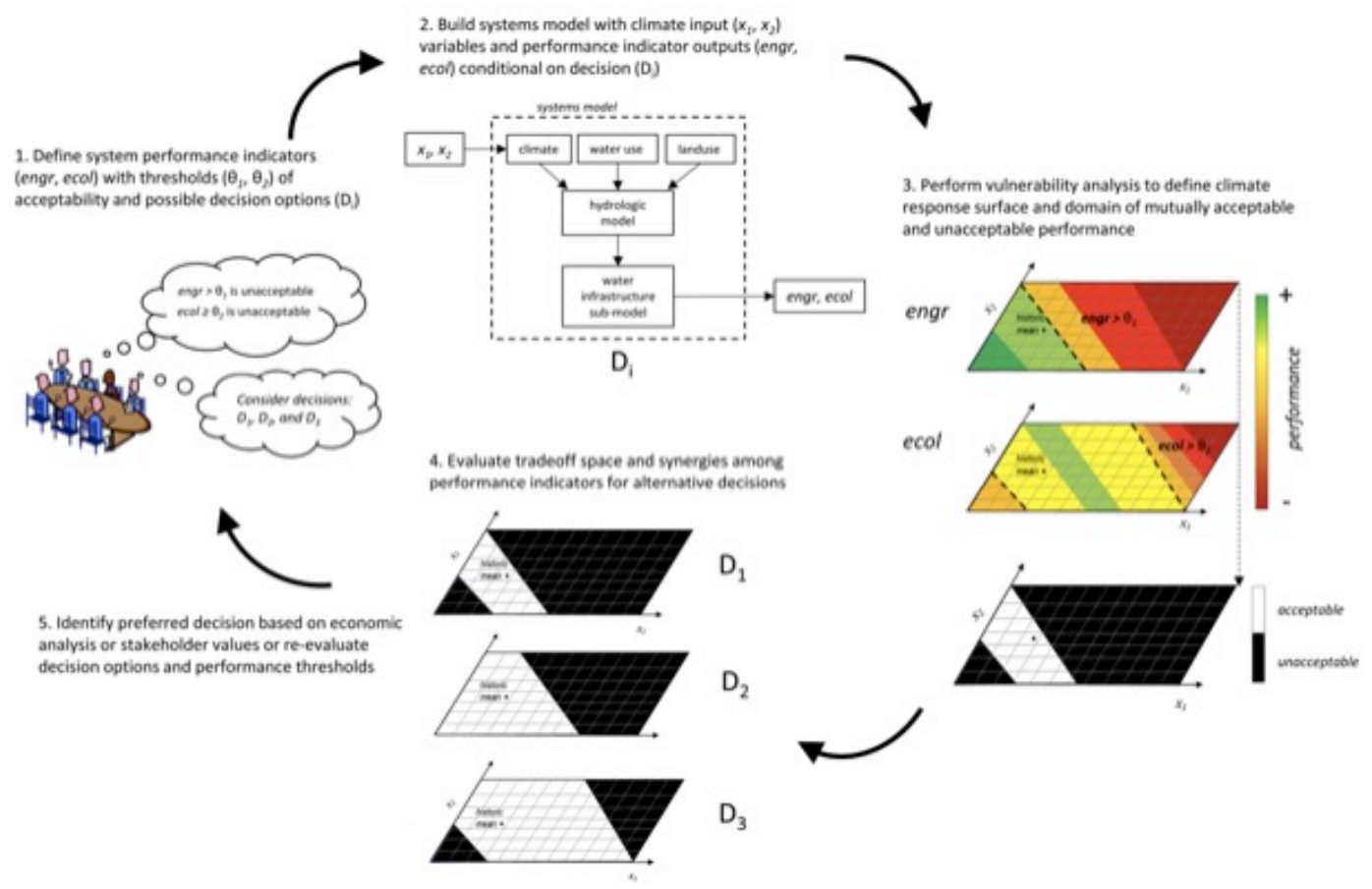


Figure 2. Iowa River study area near Iowa City, Iowa, USA showing Coralville Dam with flooding spillways and extent of 2008 flood that breached some levees in Iowa City (urban footprint shown in gray) and extensively inundated downstream floodplain farmland and riparian habitats (dark blue).

Figure 2

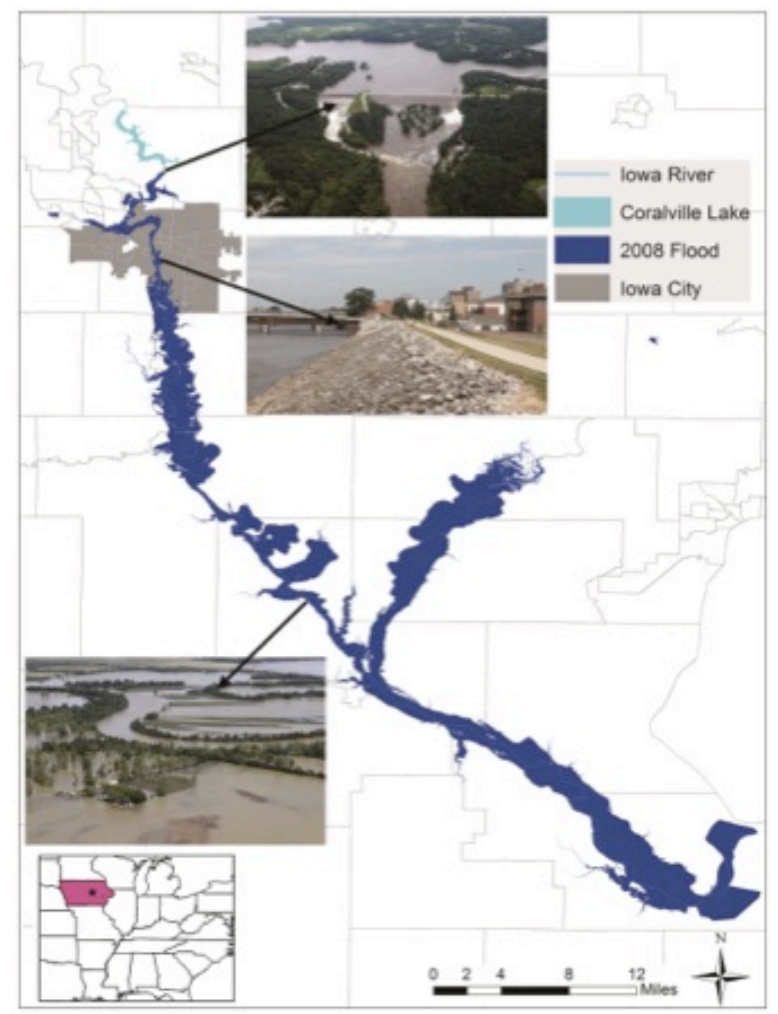


Figure 3. Iowa River system performance indicators mapped in a variable future climate space defined by change in annual precipitation variability and mean annual flow for each of 4 management actions (rows). The first column of panel a shows estimated annual costs (EAC; engineering performance indicator), expressed as values relative to the historical long-term (19592010) mean, with values exceeding the 1.5 times historical levels (above the dashed line) being unacceptable. The second column indicates the floodplain inundation area (ecological performance indicator), with values falling below the historical mean (below the dashed line at 1.0) deemed unacceptable for floodplain inundation. The overlapping domain of mutually acceptable performance for the two indicators is shown as white space in column 3. Panel b shows the second ecological performance indicator (flow recession rates), with values exceeding the threshold of $+30 \%$ of historical, unregulated inflow recession rates being unacceptable (to left of dashed line). Mutually overlapping performance for all combinations of the 3 indicators $(1$ engineering and 2 ecological) is shown in second column for each of four management actions.

Figure 3
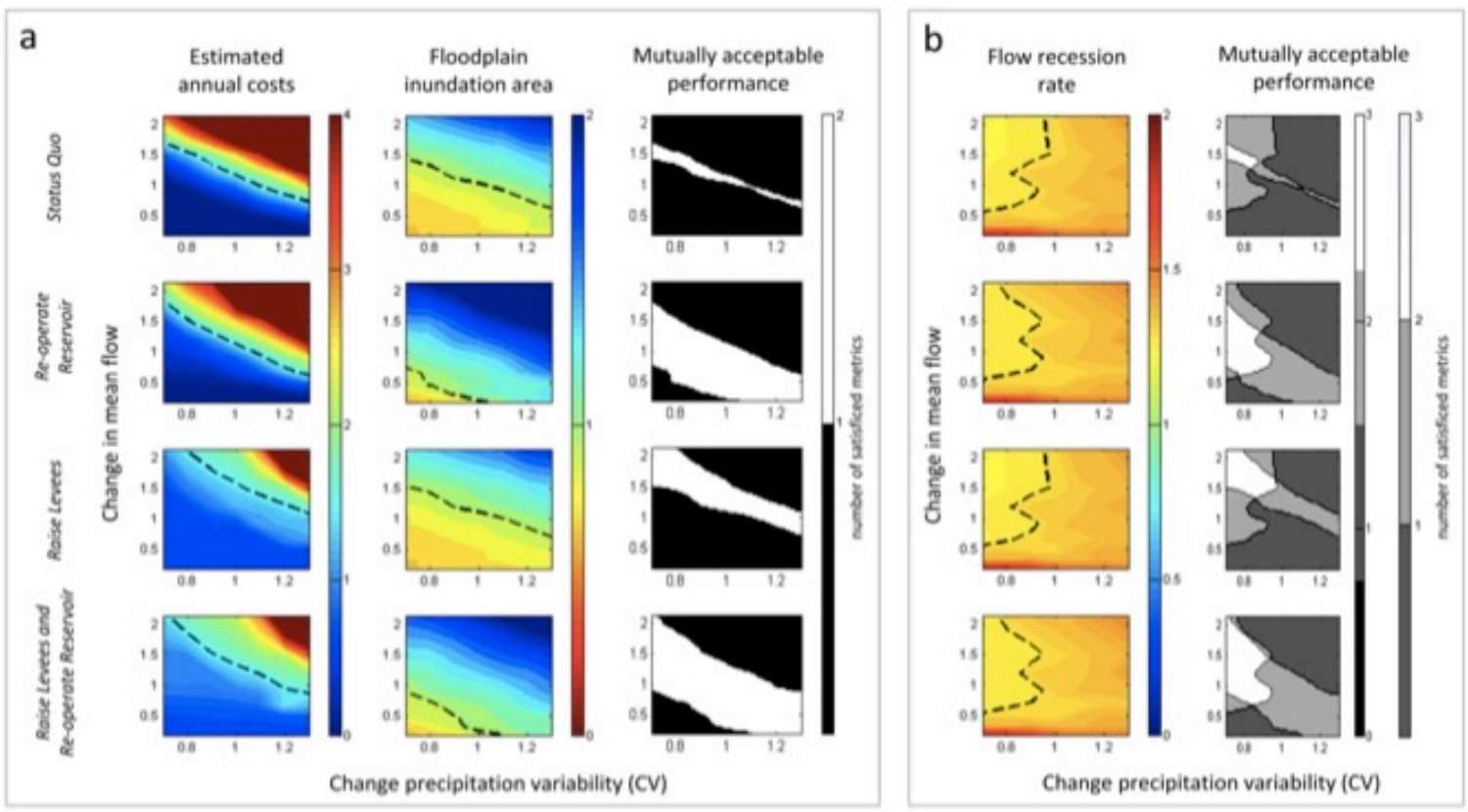